\title{
Vulnerabilidades digitais: diálogos e aproximações possiveis com os aportes teóricos barberianos da comunicação
}

Digital vulnerabilities: dialogues and possible approaches with the Barberian theoretical contributions of communication

Vulnerabilidades digitales: diálogos y posibles aproximaciones con los aportes teóricos barberianos de la comunicación

\author{
Antonio Hélio JUNQUEIRA \\ Universidade Anhembi Morumbi Sao Paulo - Brasil \\ helio@hortica.com.br \\ Rodrigo Eduardo BOTELHO-FRANCISCO \\ Universidade Federal do Paraná - Brasil \\ rodrigobotelho@ufpr.br \\ Jenifer daiane GRIEGER \\ Universidade Federal do Paraná - Brasil \\ eniferd.grieger@gmail.com
}

Chasqui. Revista Latinoamericana de Comunicación

$N .^{o}$ 147, agosto-noviembre 2021 (Sección Monográfico, pp. 161-178)

ISSN 1390-1079 / e-ISSN 1390-924X

Ecuador: CIESPAL

Recibido: 25-03-2021 / Aprobado: 10-07-2021 


\title{
Resumo
}

O artigo elabora uma discussão teórica sobre as potencialidades e a produtividade dos conceitos e estudos barberianos no campo da comunicação - especialmente dos múltiplos mapas elaborados por aquele autor no período de 1987 a 2017-, visando à compreensão dos fenômenos contemporâneos das vulnerabilidades digitais. Investiga os modos como as diferentes mediações sequencialmente mobilizadas por Martín-Barbero, ao longo de 30 anos, podem colaborar para o entendimento dos impactos dos usos e apropriações das TIC em contextos de hiperconectividade e de big data, acarretando diferentes riscos individuais e coletivos. Metodologicamente, adotamos a pesquisa bibliográfica com foco na análise crítica das abordagens de diferentes autores nacionais e internacionais sobre os fenômenos comunicacionais e informacionais envolvidos com a temática da vulnerabilidade digital.

Palavras-chave: mediações, mapas barberianos, tecnologias de informação e comunicação, ciência da Informação.

\begin{abstract}
The article elaborates a theoretical discussion about the potentialities and productivity of Barberians concepts and studies in the field of communication especially the multiple maps created by that author from 1987 to 2017-, aiming at understanding the contemporary phenomena of digital vulnerabilities. It investigates the ways in which the different mediations sequentially mobilized by Martín-Barbero, over 30 years, can collaborate to understand the impacts of the uses and appropriations of ICT in contexts of hyperconnectivity and big data, causing different individual and collective risks. Methodologically, we adopted bibliographic research with a focus on critical analysis of the approaches of different national and international authors on the communicational and informational phenomena involved with the issue of digital vulnerability.
\end{abstract}

Keywords: mediations, Barberian maps, information and communication technologies, information science.

\section{Resumen}

El artículo elabora una discusión teórica sobre las potencialidades y productividad de los conceptos y estudios barberianos en el campo de la comunicación - especialmente los múltiples mapas creados por este autor entre 1987 y 2017-, con el objetivo de comprender los fenómenos contemporáneos de las vulnerabilidades digitales. Investiga las formas en que las diferentes mediaciones movilizadas secuencialmente por Martín-Barbero, a lo largo de 30 años, pueden colaborar para comprender los impactos de los usos y apropiaciones de las TIC en contextos de hiperconectividad y big data, provocando distintos riesgos individuales y colectivos. Metodológicamente, adoptamos la investigación bibliográfica con enfoque en el análisis crítico de los enfoques de diferentes autores nacionales e internacionales sobre los 
fenómenos comunicacionales e informativos relacionados con el tema de la vulnerabilidad digital.

Palabras clave: mediaciones, mapas barberianos, tecnologías de la información y la comunicación, ciencias de la información.

\section{Introdução}

Os estudos latino-americanos no campo da Comunicação, especialmente a obra de Jesús Martín-Barbero, têm constituído, desde a década de 1980, um dos mais relevantes aportes teórico-metodológicos para as pesquisas sobre os processos comunicacionais nos contextos múltiplos, híbridos e complexos das mediações culturais, tecnológicas, políticas e socioeconômicas da contemporaneidade. Seu enorme potencial e produtividade em pesquisa nas ciências sociais, incluindo as aplicadas, têm feito com que os estudos barberianos extrapolem o campo da Comunicação, para abranger e serem também incorporados em múltiplos outros.

Ao longo deste período, o pensamento barberiano sobre as interações entre homem, sociedade e cultura não se manteve estanque, mas, ao contrário, foi se atualizando, adquirindo novas dimensões, conexões e relevâncias, ao mesmo tempo que convive com o constante desenvolvimento e com as inovações em tecnologias digitais, bem como com sua inserção cada vez mais profunda e transformadora na vida contemporânea.

O pensamento crítico sobre estas tecnologias, por sua vez, também passou, no período, pela emergência de abordagens, das apocalípticas às integradas, ora centradas em metáforas advindas da ideia de redes, ora centradas nos aspectos informacionais, comportamentais ou sociais. Daí a falarmos em Sociedade em Rede (Castells, 1999), Sociedade da Informação (Matsuda, 1982), Modernidade Líquida (Bauman, 2001), Sociedade de Controle (Deleuze, 1992), entre outras conceituações que buscam definir os tempos atuais. Independente das conceituações, as percepções do digital na cultura passam, ao longo do tempo, por compreender o desenvolvimento científico e tecnológico em sua gênese, assim como a partir de suas controvérsias. O uso de expressões como exclusão/ inclusão digital, risco e competência digital ao longo da história recente da tecnologia e do poder social comprovam um terreno de profusão de tentativas conceituais para abarcar as dimensões dos dilemas do digital.

Com a evolução da tecnologia informática e sua performance comercial entre diferentes classes sociais, no entanto, estudos sobre a posse, usos e comportamentos naturalmente foram se mostrando insuficientes para compreender o fenômeno, especialmente porque diferentes atores sociais experimentam e experienciam a tecnologia e suas narrativas de forma bastante diferentes, num ecossistema complexo e multifacetado. Por este motivo, preferimos falar, no âmbito deste trabalho, em vulnerabilidades digitais, 
alternativa conceitual que auxilia a vislumbrar múltiplas perspectivas da mediação tecnológica e social entre diferentes atores, humanos e não-humanos.

Frente a esta conceituação e buscando compreender a sua potencialidade para abarcar os fenômenos infocomunicacionais, no presente artigo visamos estabelecer diálogos e conexões da questão da vulnerabilidade digital com a teoria barberiana da Comunicação, buscando nexos e relações entre a evolução das diferentes mediações mobilizadas por Martín-Barbero e os contextos de riscos, superexposições e ameaças experimentados gradativa e cumulativamente pelo sujeito contemporâneo na sua vivência digital.

\section{Vulnerabilidades digitais: tentativas de construção de um conceito}

Os modos da existência contemporânea conformam uma sociedade já entendida e nomeada como uma sociedade de risco (Beck, 2011), ou, ainda, como habitat de sujeitos inseguros imersos em uma cultura de insegurança (Rosello, 2008).

Ao longo dos anos, riscos e inseguranças em diferentes contextos da vida social seguem engendrando conceitos que se vão amalgamando no bojo de uma ideia geral do que venha a ser a vulnerabilidade tanto individual, quanto coletiva, grupal ou global nas sociedades atuais. Trata-se de tentativas de definição de fenômenos complexos que envolvem e mobilizam simultaneamente variáveis controláveis e incontroláveis, humanas e naturais e que confluem, em múltiplos sentidos e dimensões, para as possibilidades de causarem danos físicos, morais, psíquicos e/ou espirituais aos indivíduos e grupos sociais.

Historicamente, a conceituação da vulnerabilidade ganhou contornos melhor definidos na esfera da saúde pública e a partir da necessidade de enfrentamento e controle da AIDS, nos anos 1980. A rápida disseminação global da doença instituiu a necessidade de se pensar os modos como ela se espalhava por múltiplos contextos socioeconômicos e atingia grupos e indivíduos de diferentes perfis comportamentais. Nesse contexto, a ideia de risco ou de população de risco progressivamente cede espaço para o conceito de vulnerabilidade, tanto individual quanto social.

Nesse sentido e direção, vulnerabilidade passa a agregar progressivamente, nos campos técnicos, acadêmicos, administrativos e políticos, dimensões socioeconômicas (pobreza, insegurança alimentar, fome etc.), carências de acesso e atendimento em bens e serviços públicos e/ou comunitários de primeira necessidade (educação, atendimento médico, serviços de saúde, saneamento básico e outros), suscetibilidade a riscos e danos ecológicos naturais (fenômenos associados às mudanças climáticas, tormentas, deslizamentos de terra, rompimentos de barragens e outros similares), fenômenos políticos e culturais (genocídios, guerras étnicas, intolerâncias, ódios e perseguições das mais diferentes naturezas).

No campo da Ciência da Informação, Vitorino (2018, p. 82) propõe pensar o conceito de vulnerabilidade no campo informacional, a qual define como: 
Um estado de susceptibilidade a danos causados às pessoas por excesso de exposição à informação ou falta de acesso à informação e a tensões associadas a esse fenômeno na sociedade, devido à ausência de resiliência no que concerne ao desenvolvimento das dimensões técnica, estética, ética e política da competência em informação.

Ao buscar um olhar para os conceitos de exclusão e inclusão no acesso e uso de tecnologias e redes de informação na atualidade, Funte-Cobo (2017, p. 9, tradução nossa) pondera sobre um sentido amplo do conceito de vulnerabilidade, relacionado "não somente aos que formam parte de coletivos em situação de risco de exclusão, mas também utilizado para fazer referência a indivíduos e grupos suscetíveis de sofrer danos no acesso e exposição aos meios e serviços da sociedade da informação".

Ao observar a vulnerabilidade numa zona de trânsito, Fuente-Cobo (2017) busca demonstrar como de uma situação de precariedade laboral e instabilidade em redes sociais digitais, o que caracterizaria uma zona de vulnerabilidade, se pode passar a outras duas ou três situações como as de integração (vinculadas a ideia de emprego e estabilidade em redes sociais digitais), de exclusão social ou de assistência (quando há subsídios sociais para pessoas ou grupos em situações vulneráveis

$\mathrm{Na}$ tentativa de sistematização de uma visão geral sobre o tema, vulnerabilidade pode ser entendida, enfim, como uma negatividade; como uma carência, insuficiência ou impotência humana para gerar defesa e proteção dos próprios indivíduos, grupos sociais ou de toda a humanidade frente a fenômenos ou riscos capazes de gerar prejuízos, danos ou até mesmo a perda da vida.

No campo científico, os estudos sobre vulnerabilidade vão avançando no tempo de forma fluida e constante, buscando se adequarem às complexidades sociais que se vão engendrando, sem perder de vista o caráter socioeconômico e cultural das tecnologias. Tal ordem de considerações direcionou o presente estudo para a pesquisa bibliográfica focada na análise crítica preliminar das obras de pesquisadores nacionais e internacionais que vêm se destacando na investigação do tema, em conformidade com a observação atenta e a experiência dos autores. Ao observarmos detalhadamente a abordagem destes estudos, fica evidente, também, o caráter interdisciplinar do conceito das vulnerabilidades digitais.

Nesse contexto, pensar o que poderia definir a vulnerabilidade digital torna-se desafio de largas proporções. Propomos categorizar, de maneira inicial, os estudos sobre vulnerabilidade digital encontrados e selecionados em quatro períodos sócio-históricos consecutivos e interconectados, que, no nosso entendimento, estabelecem diálogos e conexões válidas e produtivas com a sequência dos quatro mapas barberianos.

No primeiro deles, situado entre a década de 1980 e início dos anos 1990, as discussões a respeito das vulnerabilidades digitais são ainda embrionárias, 
dado que situadas em um contexto comunicativo e informacional mais analógico do que propriamente digital. $\mathrm{O}$ próprio conceito geral de vulnerabilidade encontra-se neste período sobre forte pressão conformativa de seus sentidos, impulsionado pelo drama social da saúde pública. A este período, metodologicamente corresponde o mapa barberiano das mediações n. 1, elaborado sobre a centralidade da televisão na mediação cultural da comunicação na cultura, como será detalhadamente discutido mais à frente neste texto.

No segundo momento, que neste trabalho corresponde ao período da reformulação e reapresentação do mapa barberiano das mediações n. 2, o conceito das vulnerabilidades digitais começa a ser pensado e incorporado às problemáticas mais específicas da sociedade da informação, revelando a crescente preocupação com a análise crítica da cultura em mutação, frente às inovações comunicativas e informacionais trazidas pela tecnologia. Assim, no âmbito de uma Internet já compreendida na sua segunda fase evolutiva (a web 2.0), comportamentos emergentes na Internet - principalmente por parte das populações mais jovens - passam a ser considerados de risco e adquirem expressão relevante nos estudos científicos do tema. Ransbotham et al. (2016, p. 934) propõem, num olhar retrospectivo para aquele contexto, uma definição do que entendem como vulnerabilidade digital:

Definimos vulnerabilidade digital como uma condição de suscetibilidade a danos decorrentes do uso de tecnologias digitais. O dano pode surgir da presença da própria tecnologia (por exemplo, o início de alguma condição, como technostress ou vício digital), uma externalidade do uso da tecnologia por outra pessoa (por exemplo, divulgação inadvertida ou perda de dados), ou de ação nefasta intencional (por exemplo, uma intrusão de segurança ou invasão de privacidade). Uma vulnerabilidade se manifesta quando o ataque ou condição realmente ocorre (tradução nossa).

No período que corresponde à evolução dos mapas barberianos para a sua terceira versão, por volta do início da década de 2010, as tecnologias de informação e comunicação (TIC) experimentam enorme avanço, diversidade e dispersão social, conformando um novo ecossistema comunicativo, repleto tanto de oportunidades e conquistas quanto de riscos. A ubiquidade e a mobilidade digitais adquirem primazia conferindo maior grau de liberdade informacional no espaço urbano, refazendo contornos e territorialidades determinados por fluxos, conteúdos e performances. Tudo isso não se passa, contudo, sem ameaças à privacidade e anonimato dos indivíduos, a partir de tecnologias, aparatos e formas de controle, monitoramento e vigilância.

$\mathrm{Na}$ mais recente dimensão sociocultural contemporânea, o mapa das mediações n. 4 de Martín-Barbero, corrobora os esforços para o entendimento das "mutações comunicacionais e culturais do nosso tempo" (Martín-Barbero, 2017). Nesse contexto socialmente ainda mais diversificado e complexo, as 
vulnerabilidades digitais acumulam pressões e riscos advindos de diferentes fontes que vão desde as novas potencialidades tecnológicas, gerenciais e de vigilância dos próprios dispositivos (computação em nuvem, Internet das Coisas, Inteligência Artificial, câmeras de monitoramento, algoritmos etc.) (Pariser, 2012; Gillespie, 2018), quanto das dimensões éticas advindas de novos contextos de produção e circulação de narrativas e discursos de ódio (Silva et al, 2019; Fundação Getúlio Vargas, 2021), comportamentos de incivilidade e assédios online e, ainda, de perspectivas psicológicas, decorrentes do uso excessivo e da dependência da internet (Helsper e Smahel, 2020; Virlée et al., 2020).

\section{Os mapas barberianos}

Desde a primeira edição da sua obra clássica, "Dos meios às mediações: comunicação, cultura e hegemonia”, há mais de 30 anos, Martín-Barbero instituiu o conceito de seus "mapas noturnos" para abranger a ação, os impactos e as resistências das mediações comunicativas na cultura, em suas amplas e complexas interações com o poder e suas estruturas sociais. Em conformidade com sua ideia conceitual original, o autor segue, ao longo das décadas seguintes, alterando os elementos incorporados em suas mutantes relações no tempo e no espaço, gerando novas configurações e interseções de seus mapas.

Os três primeiros e sucessivos mapas barberianos das mediações foram apresentados publicamente nas introduções de novas edições do seu livro respectivamente nos anos de 1987, 1998 e 2010. A necessidade de o autor imputar mudanças no seu mapa original decorreu das permanentes e profundas transformações da sociedade, especialmente no que tange à complexificação de suas relações com a comunicação, com a informação e com as tecnologias digitais.

Fígaro (2019) propõe pensar esses mapas barberianos de forma processual, destacando as relações de avanços de uns em relação aos outros, em perspectiva e não de forma isolada. Dessa forma, a autora sugere a superposição dos mapas, em camadas, como forma de conferir a dimensão da profundidade às análises conceituais de pesquisa, sem perder as noções de historicidade e de poder. Lopes (2018, p. 51), por sua vez, propõe que "a cartografia barberiana diz respeito a um método estratégico-rizomático e as mediações devem ser vistas como dispositivos que se entrecruzam em constante movimento de mutação, renovação e atualização".

\section{0 mapa n.1 e os anos 1980: a emergência do consumo de Internet na América Latina}

O primeiro mapa barberiano, surgido em 1980 e publicado como introdução do livro seminal do autor, na edição de 1987, tornou-se elemento chave para a discussão e compreensão das mediações culturais da comunicação, em que 
esta é epistemologicamente enfocada a partir da cultura. Em sua concepção, o autor introduziu dois eixos constitutivos: um eixo diacrônico ou histórico, entre matrizes culturais e formatos industriais e um outro sincrônico, conectando as lógicas da produção massiva e as competências de recepção ou consumo cultural (Figura 1).

Figura 1. Mapa barberiano das mediações n. 1

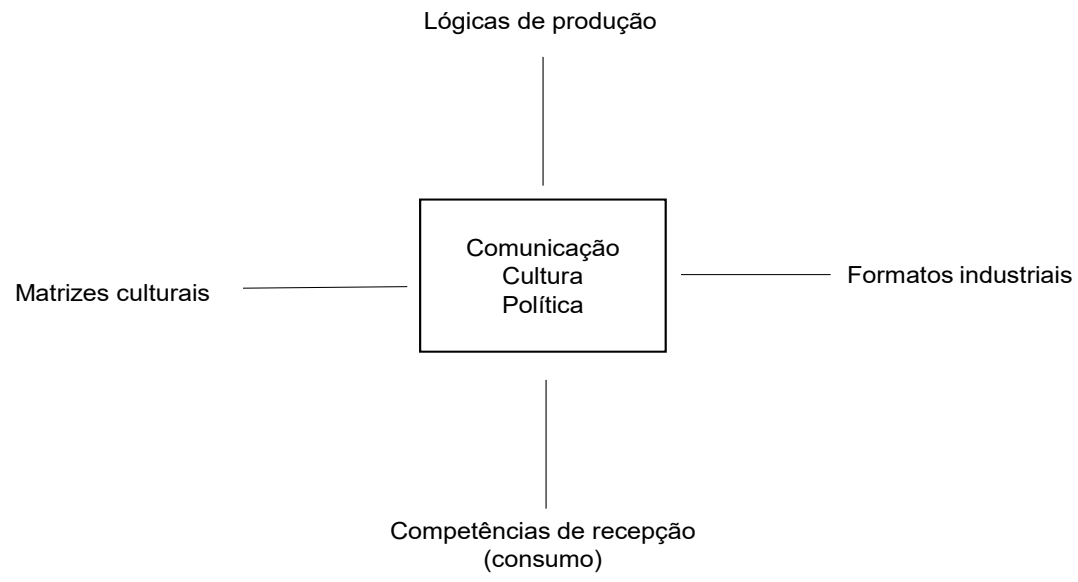

Fonte: Martín-Barbero (1987)

Vale considerar que este primeiro mapa barberiano coincide com a introdução da Internet comercial, ou Internet de consumo, na América Latina, no início dos anos 1980. Neste período, o foco principal de MartínBarbero era a televisão e suas preocupações diziam respeito especialmente às relações e às lógicas do poder que sustentavam o funcionamento dos meios de comunicação frente aos seus conceitos emergentes das mediações. Estas, por sua vez, traziam novas perspectivas aos estudos e à compreensão dos processos comunicacionais, conferindo maior centralidade à recepção. Ganhavam corpo e expressão os processos de resistência contrahegemônica aos sentidos sociais, conferindo espaços próprios às percepções, interpretações e participações dos grupos socialmente subalternizados (mulheres, indígenas e outros).

Neste período, a vulnerabilidade digital é configurada e entendida principalmente como decorrente da exclusão digital. A preocupação central será a de garantir o acesso das populações marginalizadas às Tecnologias de Informação e Comunicação (TIC) e ao consumo tecnológico. Emerge, neste período, com significativo impacto, certa visão otimista a respeito do acesso massivo às TIC e da potencial configuração de um novo formato para a distribuição social do poder da Comunicação e da Informação. Tende a prevalecer a crença em uma transposição mecanicista inquestionável do modelo 
horizontalizado e concentrado do poder da comunicação e da informação (o um-para-muitos paradigmático da comunicação de massa), para o das redes de conexão, rizomáticas, horizontalizadas, colaborativas, compartilhadas e democratizadas (de muitos-para-muitos) (Castells, 1999). Ao olhar o fenômeno, Passarelli (2010) denomina e caracteriza o fenômeno como a "primeira onda" da massificação da Internet, metáfora que irá colaborar para compreender os estágios de desenvolvimento e difusão da tecnologia digital.

Ao observar este fenômeno nos mapas barberianos, o podemos fazer pautados em três diferentes ordens de mediações, conforme ajuda identificar Lopes (2018): i) as mediações constitutivas ou fundantes (comunicação, cultura e política), que compõem uma tríade indissolúvel, a qual se vê no centro da figura e que se encontram, também, presentes nas duas versões posteriores seguintes; ii) quatro mediações básicas (matrizes culturais, formatos industriais, lógicas de produção e competências de recepção/consumo), presentes nos mapas de números 1 e 2 e substituídas por: temporalidade, espacialidade, mobilidade $\mathrm{e}$ fluxos, no mapa n. 3 ; iii) as submediações, constituídas por institucionalidade, tecnicidade, ritualidade e socialidade, no mapa de n.2, parcialmente substituídas por identidade e cognitividade no mapa n. 3 .

As mediações constitutivas ou fundantes, conforme já visto, operam em dois eixos: o diacrônico ou histórico, de longa duração, que conecta as matrizes culturais aos formatos industriais, e o sincrônico que articula as lógicas de produção às competências da recepção (consumo).

Martín-Barbero, nesse dispositivo, consolida o entendimento do funcionamento movente da sociedade, com seus laços e vínculos entre sujeitos, enquanto resultado complexo de interações ambivalentes e contraditórias entre "processos comunicacionais enquanto operadores de sentido e o mercado como operador de valor" (Lopes, 2018, p. 16).

Essa vinculação estruturada, estruturante e inextricável entre, por um lado, os dispositivos e tecnologias comunicacionais e, por outro, as lógicas e racionalidades operativas do mercado compõe a ancoragem fundamental dos mapas barberianos em sua evolução temporal, política, cultural e histórica e é, para nós, o eixo condutor principal que enceta e adensa o diálogo e a discussão da teoria barberiana da comunicação com a conceituação das vulnerabilidades digitais.

\section{O mapa n. 2 e o final dos anos 1990: a mudança cultural a partir da comunicação}

O segundo mapa foi elaborado e publicado por Martín-Barbero no prefácio à quinta edição de "Dos meios às mediações", em 1998. Este novo dispositivo criado veio a permitir a pesquisa e o estudo das mediações comunicativas da cultura, instituindo o estudo da cultura a partir da comunicação. Nele, o autor estabeleceu, por um lado, o eixo das relações entre a socialidade cotidiana (ação 
comunicativa) e a institucionalidade midiática (o escopo econômico/legal dos meios de comunicação) e, por outro, o eixo das correlações entre a tecnicidade (espessura sociocultural das novas tecnologias) e a ritualidade (ligação simbólica da comunicação contemporânea com amplas memórias, seus ritmos mestiços e ritos). (Martín-Barbero, 2018). Esta renovada concepção barberiana consolida a percepção da teoria das mediações para além da perspectiva da recepção, configurando, de fato, o processo comunicacional em sua integralidade (Figura 2).

Esse período sócio-histórico e cultural ficará caracterizado pelo fortalecimento do poder midiático e da sua progressiva naturalização no estabelecimento de novos "rituais midiáticos" (Coldry, 2003) na sociedade, especialmente a partir da televisão, com seus talk shows, reality shows e outros eventos similares. Para Coldry (2019, p. 411), trata-se do estabelecimento, pela mídia, de eventos e formas comunicativas "separadas do fluxo normal da vida comum", mas capazes de oferecer acesso especial aos valores mais importantes do mundo social.

Esse mesmo autor designará esse entendimento como o "mito do centro mediado" (Coldry, 2003), conceito que revisará ao final da década seguinte, frente ao papel crescente das plataformas digitais e da datificação como elementos estruturantes das relações sociais (Coldry, 2019). Para ele, o papel da mídia na ordenação social passará então a ser marcado pela migração do mito do centro mediado para o mito do big data.

A entrada no mercado de grandes provedores de Internet, como a AOL, nos Estados Unidos, em 1997, e a percepção do espaço digital como arena de efetivo potencial para novos negócios estimulou o desenvolvimento tecnológico e o profícuo lançamento de novas ferramentas, sites e interfaces digitais amigáveis e cada vez mais intuitivas para uso dos internautas. Com isto, inicia-se o processo de expansão das redes sociais digitais, instituindo formatos hoje amplamente conhecidos como os perfis virtuais, redes de contato e visualização de listas de outros frequentadores. Neste mesmo contexto, surgem os primeiros blogs originalmente denominados de weblogs - e os permalinks, que vieram a permitir a localização permanente das publicações digitais, bem como as conexões entre elas e a navegação hipermidiática, instaurando o espaço conhecido como blogosfera e a efetiva passagem da web 1.o para a web 2.0, na qual as ferramentas irão incorporar os universos da imagem fotográfica e dos vídeos (Flickr, Vimeo, Youtube e outros), do som e da música (MySpace, etc.) bem como um processo de adequação semântica da web, no qual a perspectivas de sites estáticos dá lugar a sistemas gerenciadores de conteúdos (CMS) e a um conjunto de tecnologias pautadas em marcação e metadados, o que popularmente ficou evidente com o uso das hashtags.

Esta perspectiva participativa na produção de conteúdos por um novo perfil de atores sociais, sem um vínculo com os meios tradicionais de comunicação e outros agentes da cadeia produtiva, chamará a atenção, também, para uma nova 
percepção sobre o universo de produção e consumo, cada vez mais difíceis de tangibilizar. Passam, então, a serem utilizados novos conceitos para tratar deste contexto, a exemplo de interagentes, interatores, prosumidores, dentre outros.

No diálogo sócio-histórico e tecnológico com o primeiro mapa barberiano, podemos pensar esse como o momento da emergência de profundos questionamentos sobre os usos e as apropriações das TIC por este novo perfil de ator em rede, tensionando a compreensão das suas competências para uma vivência digital ativa, consciente, crítica e cidadã. Este tensionamento vai dar origem à chamada "segunda onda" (Passarelli, 2010), movimento no interior do qual ficará mais evidente a emergência de novas formas para a vulnerabilidade digital dos sujeitos contemporâneos.

Nesse contexto, a vulnerabilidade digital deixa de se caracterizar apenas ou principalmente como a falta ou a precariedade de acesso aos dispositivos e às TIC, mas expande-se para abarcar as formas como esses elementos são incorporados, vivenciados, explorados e operados pelos sujeitos. Trata-se de ir além do simplesmente ter, para a dimensão do que efetivamente fazer com as tecnologias digitais de comunicação e informação. É aí que uma concepção renovada do mapa barberiano original nos ajudará a caminhar na direção de revelar novas dimensões e perspectivas para a compreensão das vulnerabilidades digitais.

Figura 2. Mapa barberiano das mediações n. 2

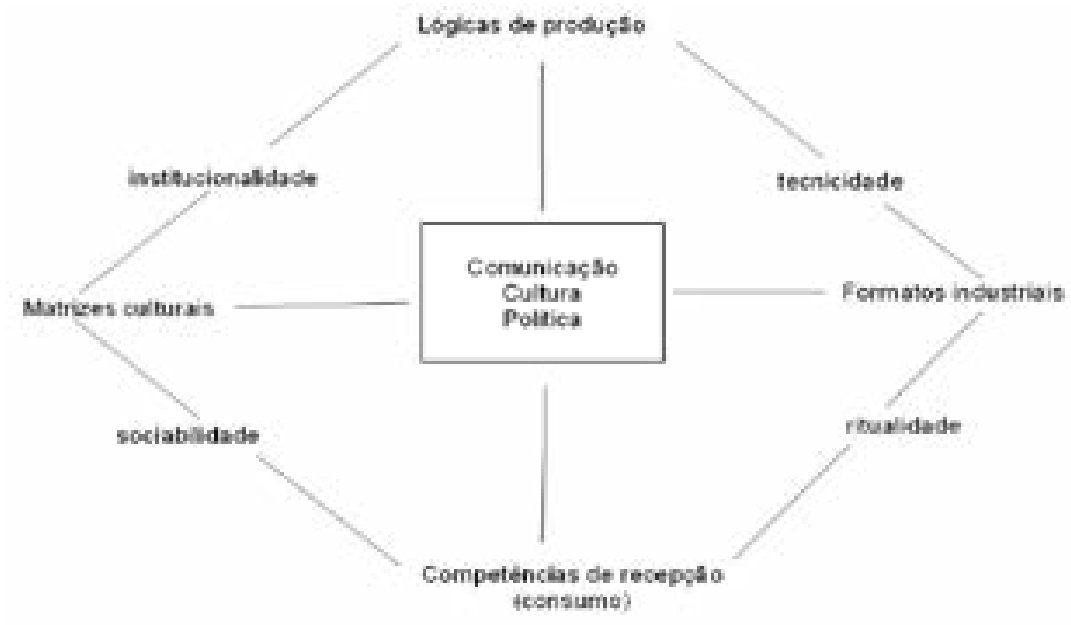

Fonte: Martín-Barbero (1998)

A conformação e a consolidação dos novos espaços sociais digitais tiveram, entre suas consequências, a maior diversificação das fontes de comunicação, informação, produção e distribuição de saberes e conteúdos, rompendo com as antigas hierarquias sociais ocupadas pela escola, pela família e 
outras instituições primárias e secundárias da conformação da socialidade contemporânea. Se, por um lado, as fontes de informação e saberes se tornaram mais amplas, abundantes, diversas, deshierarquizadas, rizomáticas e livres, por outro, o risco da des-informação, da má informação ou da informação equivocada expandiram-se enormemente, engendrando fenômenos como a pós-verdade, as fake news e os deepfakes, entre outros de natureza similar (Wardle; Derakhshan, 2017).

Nesse contexto, as vulnerabilidades digitais passam a ser configuradas, também, como a ausência ou a insuficiência de uma educação midiática capaz de gerar competências para a filtragem e seleção crítica das fontes e conteúdos (Buckingham, 2019; Costa, 2020; Romanini, 2020).

$\mathrm{Na}$ esfera das novas sociabilidades trazidas com o contexto digital, a emergência, expansão e consolidação das redes sociais digitais vão configurar um novo espaço para a conformação das identidades que, mais livres da proximidade e da vigilância dos contatos sociais diretos, ganharão outras dinâmicas e liberdades, ensejando volatilidades, transitoriedades e experimentações. Grupos e laços sociais ganharão novos contornos e geografias, pautando-se mais pela confluência de interesses e desejos do que das disposições do habitus dos grupos mais próximos de referências e das medições clássicas de classe social, gênero e etnia entre outros marcadores sociais da diferença.

$\mathrm{Na}$ dimensão negativa dessas mediações, o sujeito progressivamente se fragiliza frente aos fenômenos da perda ou da hiperexposição da intimidade (Sibilia, 2008), do cyberbullying e da experiência vivencial do isolamento social apagado nas e pelas práticas da hiperconectividade digital (Turkle, 2011).

\section{O mapa n. 3 e o início dos anos 2010: as TIC na conformação ecossistêmica da comunicação}

O terceiro mapa barberiano conecta os anteriores ao estudo das mutações culturais contemporâneas, cujos eixos componentes passam a ser os binômios: temporalidade/espacialidade e mobilidade/fluxos. Para Martín-Barbero (2010) trata-se de um modo necessário para compreender a sociedade contemporânea, na qual a tecnologia passa a configurar um novo ecossistema comunicativo. Instaura-se a primazia das relações do tempo/espaço reconfiguradas pela intensa mobilidade conferida às redes digitais ubíquas, que vieram a conferir maior grau de liberdade informacional no espaço urbano (Figura 3).

Nesse mapa, alteram-se, em relação aos anteriores, tanto as mediações básicas - agora configuradas em temporalidade, espacialidade, mobilidade e fluxos - quanto parte das submediações (identidade e socialidade).

A mediação da temporalidade institui a transformação profunda da relação social com o tempo vivido na contemporaneidade, ressaltando o culto ao presente, a fragilização das relações com o passado e a história, instituindo a primazia do atual e do simultâneo. 
Na dimensão da espacialidade, o autor incorpora a multiplicidade dos espaços habitados, especificando a confluência e a superposição dos territórios de proximidade e pertencimento, com as esferas do comunicacional tecido nas e pelas redes digitais, do imaginário de nação e identidade e da subjetividade conformada pelas novas formas do existir. A espacialidade é então configurada pelos diferentes modos como os indivíduos percebem entendem, apreendem e vivenciam os objetos e ações presentes, fixos ou em fluxo, em um dado espaço (Duarte \& Firmino, 2010). Tais fenômenos são modulados tanto pela cultura, quanto pela tecnologia, nas suas mediações com as relações sociais de poder.

Lemos (2010, p. 62) define, nesse contexto, o conceito de "território informacional” que, do ponto de vista da configuração das vulnerabilidades digitais, veio acarretar o controle de fronteiras e a instituição de ameaças à privacidade e anonimato dos indivíduos, a partir de tecnologias, aparatos e formas de controle, monitoramento e vigilância permanentes.

No eixo mobilidade/fluxos, Martín-Barbero incorpora o trânsito das migrações e das navegações virtuais dos internautas, que conformam o tempo presente. Tais movimentos são portadores da desestabilização das ordens sociais e políticas que extravasam e rompem fronteiras estabelecidas, deslocando as formas consolidadas da vida social, da produção e da transmissão dos saberes, da razão e da imaginação, da arte e da ciência, bem como da expressão e da organização de novas formas de pensar e fazer política (Castells, 2013).

Em relação à dimensão mediadora da tecnicidade, vale destacar que a sua incorporação nos mapas barberianos visa dar a necessária espessura e visibilidade ao seu papel na conformação das sensibilidades e existência do sujeito contemporâneo em novas formas de sentir, pensar, criar, aprender, expressar e interagir socialmente.

Tabela 3. O mapa barberiano das medições n. 3

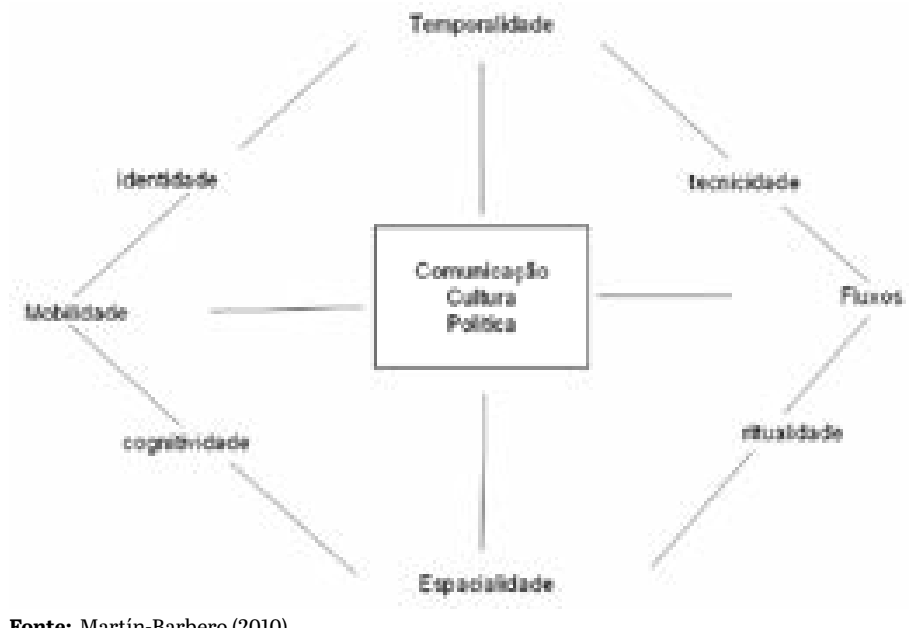

Fonte: Martín-Barbero (2010) 


\section{O mapa n. 4 os meados dos anos 2010: o novo sensorium contemporâneo}

O mapa n. 4 decorre da preocupação de Martín-Barbero em estudar as mutações comunicacionais e culturais do nosso tempo. Nele, a submediação da tecnicidade é alçada à dimensão de mediação básica, ao mesmo tempo em que a mediação da sensorialidade é introduzida, também com esse estatuto, revelando o adensamento teórico adquirido no estudo desses fenômenos no corpo estrutural e no funcionamento dialético da sociedade contemporânea (Figura 4).

Para Martín-Barbero (2017), na contemporaneidade, tecnicidade e sensorialidade não são fenômenos isolados, mas sim coproduções que mutuamente se habitam. A tecnicidade, muito mais ampla do que a técnica, é a mediação que conforma e é conformada inextricavelmente pelas novas formas de pensar, sentir, expressar, agir, comunicar, compartilhar. Nela e com ela se produz a sensorialidade que se define em termos coletivos e não individuais, instaurando novos formatos da enunciação e da performance.

Tabela 4. O mapa barberiano das mediações n. 4

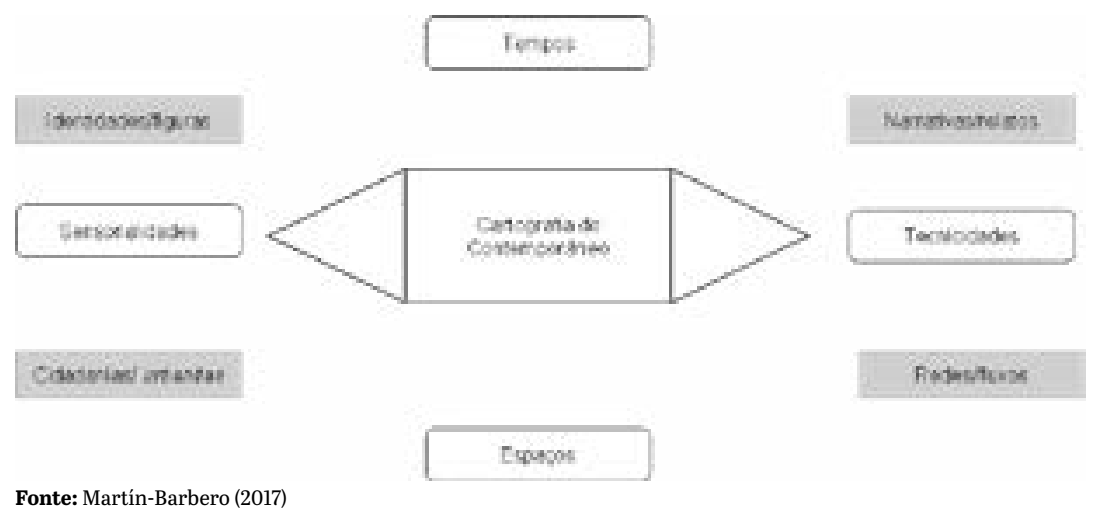

Nota-se também, e com centralidade, a conformação de novos espaços de luta entre hegemonia e contrahegemonia na configuração do entendimento das vulnerabilidades digitais. As submediações adquirem maior expressividade e papéis mais relevantes na disputa de sentidos entre sujeitos internautas e o poder imanente das empresas proprietárias das TIC, especialmente dos sites das redes sociais digitais. Assim as dimensões das narrativas/relatos, identidades e cidadanias são mapeadas e passam a integrar a mais nova versão dos mapas barberianos.

Neste campo de narrativas destacam-se, no período, os movimentos ciberativistas, que mobilizam a visibilidade de pautas de vários grupos e bandeiras do campo das vulnerabilidades sociais a partir de estratégias de 
posicionamento e ocupação de espaços on e offline, com destaque para a capacidade de se articularem via as redes sociais digitais. Exemplos deste momento ficam evidentes em movimentos como as manifestações de junho de 2013, no Brasil; a Primavera Árabe, na África do Norte; e o Occupy Wall Street, nos Estados Unidos. Ao falar sobre isto, Castells (2013) enxerga aí relevantes interações os lugares e os fluxos entre internet e redes de comunicação sem fio.

No entanto, se por um lado se ocupam as ruas e as redes com manifestações ciberativistas, por outro há uma mobilização, neste período, das instâncias formalmente constituídas, no sentido de regular a proteção dos dados pessoais dos sujeitos na forma como trafegam livremente entre as redes. É também desta época o surgimento do Regulamento Geral sobre a Proteção de Dados (GRPD) na Europa; do California Consumer Privacy Act of 2018 (CCPA), nos EUA; e da Lei Geral de Proteção de Dados Pessoais (LGPD), no Brasil, dentre outras ao redor do mundo que passaram a tentar regular o tratamento dos dados pessoais no contexto da Internet.

O período sócio-histórico da inserção desse quarto mapa barberiano é o tempo que outros autores já denominaram de era do "capitalismo de plataforma" (Srnicek, 2017) "colonialismo de dados" (Coldry \& Mejias, 2019) ou do "capitalismo de vigilância" (Zuboff, 2021). Trata-se da configuração de um novo quadro e de uma nova dinâmica social, nos quais um oligopólio composto por pouquíssimas empresas, ${ }^{1}$ as chamadas big techs, detentoras de uma imensa dimensão de negócios dedica-se à extração massiva de dados pessoais utilizados em benefício próprio, na exploração de um "mercado dos comportamentos futuros" (Zuboff, 2021). Neste contexto, o lado mais perverso da equação é composto pela livre, ativa, colaborativa e engajada participação mais ou menos consciente dos próprios internautas e cidadãos na oferta dos seus dados pessoais, sobre os quais não tem controle e dos quais pouco se beneficia.

$\mathrm{O}$ crescimento e a disseminação do uso das redes sociais digitais, enquanto mídias distribuídas, não centralizadas, favorece a disputa social pelas narrativas sociais. $\mathrm{O}$ fenômeno vem sendo denominado de netwar (guerra em rede), no interior do qual movimentos sociais, grupos não dominantes organizados adquirem o poder de disputar a "verdade" com instituições centralizadas e poderosas, até mesmo o próprio Estado. A vulnerabilidade emergente deste contexto reporta-se à legitimação das fontes da informação, valores, sentidos e conceitos que sujeitam a própria "verdade" à simples "opinião", ou a "vontades de verdade" enviezadamente interessadas e materializadas em contradiscursos (Fraser, 1990).

Há vários outros elementos em evidência no mesmo período sócio-histórico deste mapa e que constituem um verdadeiro campo em aberto, uma vez que está em curso a experimentação de um amplo mercado consumidor de tecnologias digitais disruptivas, pautadas na ampliação de aplicações no contexto do Big

1 Alphabet Inc. (Google), Apple, Facebook, Amazon e Microsoft. 
Data e na popularização de ferramentas de Inteligência Artificial, Machine Learning e Internet das Coisas. Um mercado pautado nestes fenômenos, por sua vez, tende a sinalizar o aprofundamento das vulnerabilidades digitais que discutimos neste artigo, carecendo de seu apontamento neste mapa barberiano ou outro que venha a sucedê-lo nesta constante tentativa de cartografar o contemporâneo.

\section{Considerações finais}

As vulnerabilidades digitais, conforme apontadas e discutidas neste artigo, devem ser entendidas como portadoras de um conceito fluido, em permanente evolução, na busca de dar conta, principalmente, do entendimento e do enfrentamento das fragilidades humanas frente às complexidades dos ambientes híbridos compostos por humanos e não-humanos em permanente interação. Devem ser compreendidas em perspectiva sócio-histórica que contemple simultaneamente as lutas hegemônicas e contrahegemônicas do poder social, ao par da evolução tecnológica e das lógicas e estratégias do mercado.

Na sua dimensão evolutiva, o estudo das vulnerabilidades digitais aponta para o fato de que a concepção rizomática dos mapas barberianos torna-se pertinente e produtiva, principalmente pelo caráter não hierarquizado das mediações frente aos diferentes objetos e interesses de pesquisa. Assim, os deslocamentos de posições e de amplitudes das diferentes mediações conformam mobilidades e flexibilidades, necessárias para o entendimento da evolução dos processos comunicacionais e informacionais no tempo e no espaço, sem perder de vista a historicidade e as vinculações socioculturais e políticas dos fenômenos, no interior dos quais inserem-se os indivíduos na contemporaneidade.

A crescente superposição das vulnerabilidades digitais aponta, ainda, para a urgente e incontornável necessidade de amplas e abrangentes políticas de educação midiática dos indivíduos, enquanto práticas viabilizadoras de uma nova cultura da comunicação, produção, circulação e consumo de conteúdos, e como formas inextricáveis da construção, promoção e defesa de uma sociedade efetivamente democrática e plural. Trata-se de buscar, garantir e gerir, simultaneamente, a participação ativa, crítica e consciente dos sujeitos na sociedade e a governança dos dispositivos, ferramentas e tecnologias de comunicação e informação.

Como podemos notar, o método é pujante e se mostra promissor. No entanto, a cartografia que propomos neste artigo não deve ser considerada como acabada, uma vez que há o viés de sua construção argumentativa e ensaísta no contexto e limitações desta publicação. As características do objeto em observação, por sua vez, deixam evidente que se trata de um fenômeno contraditório e complexo, que carece de múltiplos, recorrentes e diversos pontos de mirada, o que deixa, aqui, como demanda para trabalhos futuros. 


\section{Referências bibliográficas}

Bauman, Z. (2001). Modernidade líquida. Rio de Janeiro: J. Zahar.

Beck, U. (2011). Sociedade de risco: rumo a uma outra modernidade. São Paulo: Editora 34.

Bruno, F. (2008) Monitoramento, classificação e controle nos dispositivos de vigilância digital. Famecos, Porto Alegre, n. 36, p.10-16.

Buckingham, D. (2019). Teaching media in a 'post-truth' age: fake news, media bias and the challenge for media literacy education. Cultura y Educación, Vol. 31, n. 2. p. 213-231.

Castells, M. (1999). A sociedade em rede. Vol. 1. A era da informação: economia, sociedade e cultura. São Paulo: Paz e Terra.

Castells, M. (2013). Redes de indignação e esperança: movimentos sociais na era da internet. Rio de Janeiro: Zahar.

Costa, M. C.; Romanini, A. V. (2020). A educomunicação na batalha contra as fake news. Comunicação \& Educação, Vol. 24, n. 2, p. 66-77.

Couldry, N. (2019). Do mito do centro mediado ao mito do big data: reflexão sobre o papel da mídia na ordem social. Comunicação, Mídia e Consumo, Vol.16, n. 47, p. 407-431, det./dez

Couldry, N. (2003). Media rituals: A critical approach. London: Routledge.

Couldry, N.; Mejias, U. A. (2009). The costs of connection: how data is colonizing human life and appropriating it for capitalism. Stanford, CA: Stanford University Press.

Deleuze, G. (1992). Post-Scriptum sobre as sociedades de controle. In Conversações 19721990. Rio de Janeiro: Ed. 34.

Duarte, F., \& Firmino, R. (2010). Espaço, visibilidade e tecnologias: (re)caracterizando a experiência urbana. In Bruno, F., Kanashiro, M., \& Firmino, R. Vigilância e visibilidade: espaço, tecnologia e identificação. Porto Alegre: Sulina, 2010, p. 95-112.

Fígaro, R. (2019). Potencial explicativo dos estudos de recepção no contexto do Big Data. Intercom RBCC, Vol. 42, n. 3, p. 223-237, set./dez. 2019.

Fraser, N. (1990). Rethinking the public sphere: a contribution to the critique of actually existing democracy. Social Text, n. 25/26, pp. 56-8.

Fundação Getúlio Vargas (FGV). (2021). Diretoria de Análise de Políticas Públicas. DAPP. Discurso de ódio em ambientes digitais: definições, especificidades e contexto da discriminação online no Brasil, a partir do Twitter e do Facebook. Rio de Janeiro: FGV/DAPP.

Funte-Cobo, C. (2017). Públicos vulnerables y empoderamiento digital: el reto de una sociedad e-inclusiva. Profesional de la Información, Vol. 26, n. 1, p. 5-12, 4.jan. 2017.

Helsper, E. J., \& Smahel, D. (2020). Excessive internet use by young Europeans: psychological vulnerability and digital literacy? Information Communication and Society, 23(9), 1255-1273.

Lemos, A. (2010). Mídias locativas e vigilância. Sujeito inseguro, bolhas digitais, paredes virtuais e territórios informacionais. In Bruno, F., Kanashiro, M., \& Firmino, R. Vigilância e visibilidade: espaço, tecnologia e identificação. Porto Alegre: Sulina, p. 61-93.

Lopes, M. I. V (2018a). A teoria barberiana da comunicação, MATRIZes, Vol. 12, n. 1, p. 39-63.

Lopes, M. I. V (2018b). Jesús Martín-Barbero e os mapas essenciais para compreender a comunicação, Intexto, Porto Alegre, n.43, v.14-23, set./dez.

Martín-Barbero, J. (1987). De los medios a las mediaciones. Comunicación, cultura y hegemonía. Barcelona: Gustavo Gili.

Martín-Barbero, J. (1988). De los medios a las mediaciones. Comunicación, cultura y hegemonía. Bogotá: Convenio Andrés Bello. 
Martín-Barbero, J (2010a). De los medios a las mediaciones. Comunicación, cultura y hegemonía. Barcelona: Anthropos/ Universidad Autónoma Metropolitana de México.

Martín-Barbero, J. (2018). Dos meios às mediações: 3 introduções, MATRIZes, Vol.12, n.1, p. 9-31, jan./abr.

Martín-Barbero, J. (2010b). Introducciones de los medios a las mediaciones. Bogotá: Centro de Competência em Comunicación para América Latina/Fundación Friedrich Ebert.

Matsuda, Y. (1982). A sociedade da informação como sociedade pós-industrial. Rio de Janeiro: Ed. Rio.

Pariser, E. (2012) O filtro invisível: o que a internet está escondendo de você. Rio de Janeiro: Zahar.

Passarelli, B. (2010). Literacias emergentes nas redes sociais: estado da arte e pesquisa qualitativa no Observatório da Cultura Digital. In Passrelli, B., \& Azevedo, J. (Org.), Atores em rede: olhares luso-brasileiros. São Paulo: Editora Senac São Paulo.

Ransbotham, S., Fichman, R. G., Gopal, R., \& Gupta, A. (2016). Special section introduction: Ubiquitous IT and digital vulnerabilities. Information Systems Research, 27(4), 834-847.

Recuero, R. (2013). Atos de ameaça à face e à conversação em redes sociais na internet. In Primo, A. (Org.), Interações em rede. Porto Alegre, p. 51-69.

Rincón, O., \& Martín-Barbero, J. (2019). Mapa Insomne 2017. Ensayos sobre el sensorium contemporáneo. In Rincón, O., Jacks, N., Schmitz, D., \& Wotrich, L. (Org.), Um mapa para investigar la mutación cultural: dialogo con la propuesta de Jesús Martín-Barbero. Quito: Ciespal, p. 17-24.

Sibilia, P. (2008). O show do eu: a intimidade como espetáculo. Rio de Janeiro: Nova Fronteira. Srnicek, N. (2017). Platform capitalism. Cambridge: Polity Press.

Turkle, S. (2011). Alone Together: Why We Expect More From Technologyand Less From Each Other. New York, Basic Books.

Vitorino, E. V. (2018). A competência em informação e a vulnerabilidade: construindo sentidos à temática da "vulnerabilidade em informação", Ciência da Informação, Brasília, DF, Vol. 47, n. 2, p. 71-85, mai./ago.

Zuboff, S. A era do capitalismo de vigilância: a luta por um futuro humano na nova fronteira do poder". Rio de Janeiro: Intrínseca, 2021. 